\title{
PENGGUNAAN MEDIA PENGAJARAN UNTUK \\ MENINGKATKAN PRESTASI BELAJAR MATA PELAJARAN PPKn \\ PADA SISWA KELAS X SEMESTER I SMK NEGERI 1 BENDO \\ KECAMATAN BENDO KABUPATEN MAGETAN \\ TAHUN AJARAN 2014/2015
}

\section{Suprihatin $^{*}$}

\begin{abstract}
Abstrak
$\mathrm{P}$ engajaran pendidikan kewarganegaraan di sekolah bertujuan agar siswa dapat memperoleh kemampuan berfikir logis dan kritis. Melalui pengajaran pendidikan kewarganegaraan, siswa mampu mengembangkan kemampuan untuk berfikir secara logis dan memiliki keterampilan berfikir kritis dalam kehidupan sehari - hari. Pembelajaran dengan media pengajaran dapat mengubah pembelajaran dari teacher center menjadi student centered. Guru mampu menguasai dan terampil dalam melatih keterampilan proses yang digunakan dalam pembelajaran. Pembelajaran dengan media pengajaran dapat meningkatkan proporsi jawaban benar siswa serta sebagian tujuan pembelajaran khusus yang dirumuskan tuntas.

Menimbulkan motivasi belajar, interaksi yang lebih langsung antara siswa dan lingkungannya, dan memungkinkan siswa untuk belajar sendiri sesuai dengan kemampuan dan minatnya, sehingga berpengaruh positif terhadap aktivitas belajarnya dikelas.

Respon siswa terhadap komponen Kegiatan Belajar Mengajar yaitu berminat mengikuti pembelajaran berikutnya jika digunakan media pengajaran. Hasil belajar siswa yang diajar pembelajaran dengan media pengajaran lebih baik dari pada siswa yang diajar tidak menggunakan media pengajaran.

Keberhasilan penyampaian pembelajaran pendidikan kewarganegaraan sangat tergantung kreatifitas guru bagaimana guru mendesain strategi pembelajarannya, bukan pada teori - teori yang ada dalam karya tulis ini.
\end{abstract}

\section{Kata kunci :Media Pengajaran, Prestasi Belajar PKn}

* Guru PPKn SMK Bendo 


\section{PENDAHULUAN}

Media pengajaran merupakan alat yang digunakan guru ketika mengajar untuk membantu memperjelas materi pelajaran yang disampaikan kepada siswa, dan mencegah terjadinya verbalisme pada diri siswa. Pengajaran yang banyak menggunakan vebalisme, tentu akan membosankan, sebaliknya pengajaran akan lebih menarik bila siswa gembira dalam belajar atau senang karena merasa tertarik dan mengerti pelajaran yang diterimanya. Dengan demikian Kegiatan Belajar Mengajar akan lebih efektif.

Belajar yang efektif harus dimulai dari pengalaman langsung atau pengalaman kongrit dan menuju kepada pengalaman yang lebih abstrak. Belajar akan lebih efektif jika dibantu dengan alat peraga dalam pengajaran dari pada tanpa dibantu dengan alat pengajar. Agar proses belajar mengajar dapat berhasil dengan baik, siswa sebaliknya diajak untuk memanfaatkan semua alat indranya. Guru berusaha untuk menampilkan rangsangan ( stimulasi ), yang dapat diproses dengan berbagai indera. Semakin banyak alat indra yang digunakan untuk menerima dan mengolah informasi, maka semain besar kemungkinan informasi tersebut dimengerti dan dapat dipertahankan dalam ingatan.

Hemalik ( 1986 ) mengatakan bahwa pemakaian media pengajaran dalam proses belajar mengajar dapat memangkitkan keinginan dan minat yang baru, membangkitkan motivasi dan rangsangan kegaitan belajar, dan bahkan membawa pengaruh pengaruh psikologi terhadap siswa.

Dengan demikian, siswa diharapkan akan dapat menerima dan menyerap dengan mudah dan baik pesan - pesan dalam materi yang disajikan. Untuk memanfaatkan semua alat indra dalam Kegiatan Belajar Mengajar diperlukan rangsangan (stimulus). Sedangkan rangsangan tersebut dapat direalisasikan dengan penggunaan peraga dalam pendidikan. Peraga dalam pengajaran bias disebut dengan media pengajar.

Hal ini ditegaskan oleh arsyad ( 2003), yang mengatakan bahwa, kegaitan belajar mengajar pemakaian kata media pengajar digantikan olej istilahnya seperti alat pandang - dengar, bahan pengajaran, 
komunikasi pandang dengar, dalam penelitian tindakan ini, pendidikan alat peraga pandang, khususnya pada upaya meningkatkan teknologi pendidikan, alat peraga, minat belajar siswa Kelas X SMK dan media media penjelas. negeri 1 BENDO, Kabupaten Perkembangan ilmu pengetahuan dan Magetan.

teknologi semakin mendorong upaya - upaya pembaharuan dalam pemanfaatan hasil - hasil teknologi dalam proses belajar. Guru dituntut agar menggunakan alat - alat yang dapat disediakan oleh sekolah, tidak menutup kemungkinan bahwa alat alat tersebut sesuai dengan perkembangan dan tuntutan zaman. Guru harus dapat menggunakan alat yang murah dan efesien meskipun sederhana dan besahaja tetapi merupakan keharusan dalam upaya mencapai tujuan pengajaran yang diharapkan ( Arsyad, 2003 ).

Dengan penelitian tindakan kelas yang dilakukan peneliti tersebut, maka muncul beberapa permasalahan dalam kegaitan penelitian ini. Mengapa media pengajaran sangat penting digunakan dalam upaya meningkatkan minat belajar siswa dalam rangkaian kegaitan belajar mengajar ? apakah dampak penggunaan media pengajaran dalam kegaitan belajar mengajar ? hal ini perlu dibuktikan

\section{METODE PENELITIAN}

\section{Rancangan Penelitian}

Rancangan dalam penelitian mi adalah rancangan penelitian tindakan. Penelitian tindakan merupakan merupakan intervensi skala kecil terhadap tindakan dunia nyata dan pemeriksaan cermat terhadap pengaruh intervensi tersebut (Cohen dan Mantion, (1980) yang dikutip oleh Zuriah, (2003).

Rancangan dalam penelitian mi direncanakan melalui beberapa tahap perencanaan, diantarannya: (1) refleksi awal, (2) peneliti merumuskan permasalahan secara operasional, (3) peneliti merumuskan hipotesis tindakan, dan (4) menetapkan dan merumuskan rancangan tindakan.

\section{Penyiapan Partisipan}

Penelitian ini dilandasi prinsip kolaboratif, partisipatoris, dan kooperatif, maka kegiatan penyiapan partisipan dipandang perlu 
dilakukan. Kegiatan pelatihan diawali dengan kegiatan diskusi tentang penggunaan media pengajaran dalam proses belajar mengajar siswa Kelas X SMK Negeri 1 BENDO Kabupaten Magetan.

\section{HASIL PENELITIAN}

Berdasarkan pada kegiatan penelitian tindakan yang dilakukan oleh peneliti dalam penelitian yang berjudul Meningkatkan Minat Belajar Pendidikan

Kewarganegaraan Pokok Bahasan Hukum dan Peradilan Nasional pada Siswa Kelas X SMK Negeri 1 BENDO dengan Menggunakan Media Pengajaran Semester I Tahun Pelajaran 2014/2015. Penelitian Tindakan Siswa Kelas X SMK Negeri 1 BENDO Kabupaten Magetan, maka akan dipaparkan paparan data dan hasil penelitian. Adapun penjabarannya sebagai berikut:

\section{Metode Pengumpulan Data}

Berdasarkan hasil dan pengamatan dan observasi peneliti maka, dapat dipaparkan hasil penelitian tindakan (action research) berdasarkan desain pembelajaran dengan media pengajaran (peraga) yang digunakan sebagai strategi belajar siswa Kelas X SMK Negeri 1 BENDO Kabupaten Magetan. Adapun uraiannya meliputi beberapa hal sebagai berikut:

\section{Minat Belajar Siswa}

Dengan penggunaan media pengajaran (peraga) dalam kegiatan belajar mengajar untuk siswa Kelas $X$ SMK Negeri 1 BENDO Kabupaten Magetan didapatkan hasil penelitian tindakan yang menyatakan bahwa dengan menggunakan media pengajaran, minat belajar siswa Kelas X SMK Negeri 1 BENDO Kabupaten Magetan menunjukkan kemajuan yang berarti. Hal mi dibuktikan dan catatan hasil observasi peneliti selama kegiatan penelitian tindakan kelas berlangsung, pada saat wawancara dengan santai (tanpa menunjukkan melakukan penelitian) maka, dan 40 siswa yang mengatakan senang terhadap kegiatan belajar mengajar 
dengan cara mi ada 34 siswa.

Sedang akan 6 siswa lainnya tidak memiliki minat terhadap kegiatan belajar tersebut, dengan alasan masih takut.

Data hasil catatan observasi tersebut bila didistribusikan dalam tabel adalah sebagai berikut:

Tabel 1

Pernyataan Minat Belajar Siswa

Terhadap Media Pengajaran

Siswa Kelas X SMK Negeri 1

BENDO Kabupaten Magetan

Semester 1

Tahun Pelajaran 2014/2015

\begin{tabular}{|c|c|c|c|c|}
\hline No & Pernyataan & Ya & Tidak & keterangan \\
\hline 1 & Senang & $\begin{array}{c}34 \\
\text { siswa }\end{array}$ & - & $\begin{array}{c}\text { Data } \\
\text { diperoleh }\end{array}$ \\
\hline 2 & Tidak senang & - & $\begin{array}{c}6 \\
\text { siswa }\end{array}$ & $\begin{array}{c}\text { dari } \\
\text { wawancara }\end{array}$ \\
\hline
\end{tabular}

Dan tabel tersebut, membuktikan bahwa minat siswa Kelas X SMK Negeri 1 BENDO Kabupaten Magetan dalam belajar tergolong tinggi. Hal mi dipengaruhi oleh teknik pembelajaran yang digunakan oleh guru, yaitu media pengajaran. Dan 40 siswa, sebanyak 34 siswa yang memiliki minat belajar terhadap materi yang diajarkan melalui media pengajaran dengan prosentase $85.00 \%$

Tabel tersebut bila dipaparkan dalam bentuk grafik, didapatkan hasil sebagai berikut:

\section{Grafik 1}

Hasil Observasi dan Wawancara Minat Belajar

Siswa Kelas X SMK Negeri 1

BENDO Kabupaten Magetan

Tentang Minat Terhadap Materi

Yang Diajarkan Dengan Media Pengajaran

Semester I Tahun Pelajaran

$2014 / 2015$

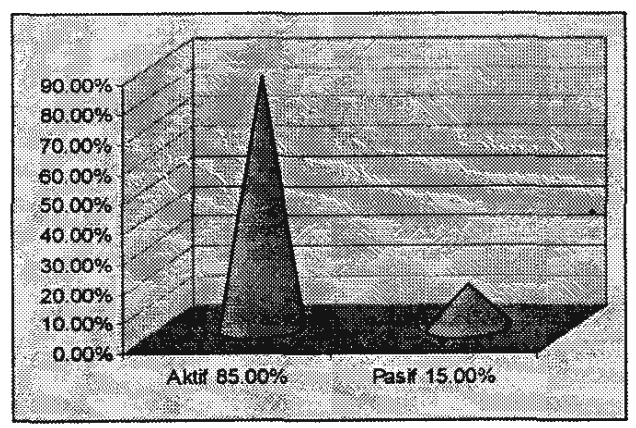

\section{Prestasi Belajar Siswa}

Berdasarkan pada hasil kegiatan penelitian, maka untuk membuktikan keefektifan media pengajaran (peraga) dalam kegiatan belajar mengajar, maka akan dipaparkan hasil belajar yang 
didapatkan oleh siswa Kelas $\mathrm{X}$ SMK Negeri 1 BENDO

Kabupaten Magetan dalam belajar.

Tabel 3

Daftar Hasil Presasi Belajar

Siswa Kelas X

SMK Negeri 1 BENDO

Kabupaten Magetan

Semester I Tahun Pelajaran

2014/2015

\begin{tabular}{|c|l|c|}
\hline No & \multicolumn{1}{|c|}{ Nama } & Nilai \\
\hline 1 & $\begin{array}{l}\text { ADITYARI DYAH } \\
\text { KRISTANTI }\end{array}$ & 5.8 \\
\hline 2 & AJENG PUTRI S. & 6.5 \\
\hline 3 & AL. FIRDA NUR AKH. & 9.2 \\
\hline 4 & ANITA INDRIANI & 8.5 \\
\hline 5 & ANTONIUS EKO Y. & 8.5 \\
\hline 6 & ANY MUSTIKA SARI & 10 \\
\hline 7 & AULIA DESIREE & 6.4 \\
\hline 8 & AYU LARASATI & 5.7 \\
\hline 9 & AYU PURNAMA SARI & 6.3 \\
\hline 10 & $\begin{array}{l}\text { AYYUDYA BELLA } \\
\text { PUSPITA }\end{array}$ & 6.7 \\
\hline 11 & BAGUS SUSILO & 10 \\
\hline 12 & BAGUS WIJAYA KP & 8.8 \\
\hline 13 & CHARLES BLANOV H.P & 5.5 \\
\hline 14 & $\begin{array}{l}\text { CINDY YOGITA } \\
\text { LODENA }\end{array}$ & 6.8 \\
\hline 15 & DANIA ULFAH DIANTI & 9.5 \\
\hline 16 & $\begin{array}{l}\text { DANIE ARI } \\
\text { WICAKSONO }\end{array}$ & 6.1 \\
\hline & PRATIS WAHYU & \\
\hline & & \\
\hline 17 & \\
\hline
\end{tabular}

\begin{tabular}{|c|l|c|}
\hline 18 & DOPI BRAMANTO & 9.2 \\
\hline 19 & $\begin{array}{l}\text { DWI APRILIANA NUR } \\
\text { RS }\end{array}$ & 6.2 \\
\hline 20 & $\begin{array}{l}\text { EDGAR RANDY } \\
\text { RENATA }\end{array}$ & 5.6 \\
\hline 21 & $\begin{array}{l}\text { HENDRIKUS } \\
\text { KURNIAWAN }\end{array}$ & 6.8 \\
\hline 22 & HILDA ANDRIANI & 6.7 \\
\hline 23 & IRFAH HIRZI & 9.5 \\
\hline 24 & NANDI PRATIKO & 7.1 \\
\hline 25 & MAD HANGGA D.P & 6.8 \\
\hline 26 & MARENTHA EKA KD & 9.1 \\
\hline 27 & MILKA APRILLITA & 7.8 \\
\hline 28 & NYOMAN ASTITI PUTRI & 8.5 \\
\hline 29 & PATRIA WIDIANTO & 8.4 \\
\hline 30 & PRISSYLINA & 9.2 \\
\hline 31 & REINALDI AGUSTA & 5.8 \\
\hline 32 & SITA HERLINDAYANI & 7.1 \\
\hline 33 & SITI ASMANIYAH & 7.5 \\
\hline 34 & SUCI ERINDA D & 7.5 \\
\hline 35 & $\begin{array}{l}\text { TUBAGUS ALDI } \\
\text { YANATA }\end{array}$ & 9.5 \\
\hline 36 & VALERIA GLINCAH N.P & 5.5 \\
\hline 37 & $\begin{array}{l}\text { WANGSYTA UMBARA } \\
\text { TYSNA }\end{array}$ & 6.7 \\
\hline 38 & $\begin{array}{l}\text { WENING } \\
\text { PANDARATJAJATI }\end{array}$ \\
\hline 39 & $\begin{array}{l}\text { WIDI WINTANG } \\
\text { PRATIWI }\end{array}$ & 8.5 \\
\hline 40 & ZELTIA YULIS TINA & 8.5 \\
\hline & Jumlah & $\mathbf{3 0 4 . 1}$ \\
\hline
\end{tabular}


Dan data tersebut dapat didistribusikan frekuensi hasil belajar siswa Kelas X SMK Negeri 1 BENDO Kabupaten Magetan sebagai berikut:

Tabel 3

Prosentase Hasil Belajar Siswa Kelas X

SMK Negeri 1 BENDO

Kabupaten Magetan

Dalam Kegiatan Belajar

Mengajar Semester I Tahun

Pelajaran 2014/2015

\begin{tabular}{|c|c|c|c|c|}
\hline No & Nilai & Frekwensi & $\begin{array}{c}\text { Frekwensi } \\
\%\end{array}$ & $\begin{array}{c}\text { Kategori } \\
\text { prestasi } \\
\text { belajar }\end{array}$ \\
\hline 1 & $\begin{array}{c}8,01 \\
- \\
10,00\end{array}$ & 17 & $42,50 \%$ & Baik \\
\hline 2 & $\begin{array}{c}6,01 \\
- \\
8,00\end{array}$ & 16 & $40,00 \%$ & Sedang \\
\hline 3 & $\begin{array}{c}0,01 \\
-\end{array}$ & 7 & $17,50 \%$ & Kurang \\
\hline \multicolumn{2}{|r|}{ T o t a l } & $\mathbf{4 0}$ & $\mathbf{1 0 0 . 0 0 \%}$ & \\
\hline
\end{tabular}

Dan frekuensi data tersebut diketahui kategori kurang dalam prestasi belajar adalah 0,01-6,00 dengan frekuensi 7 dan prosentase $17.50 \%$, kategoni nilai sedang adalah 6,01-8,00 dengan frekuensi 16 dan prosentase

$40.00 \%$, sedangkan kategori hasil belajar baik 8,01-10,00 dengan frekuensi 17 dan prosentase $42.50 \%$

Dan data prosentase hash belajar tersebut, dapat dipaparkan dalam bentuk grafik sebagai berikut:

\section{Grafik 2}

Prestasi Belajar Siswa Kelas X SMK Negeri 1 BENDO

Kabupaten Magetan Tentang

Minat Terhadap Materi Yang

Diajarkan Dengan Media

Pengajaran Dalam Kegiatan

Belajar Semester I Tahun

Pelajaran 2014/2015

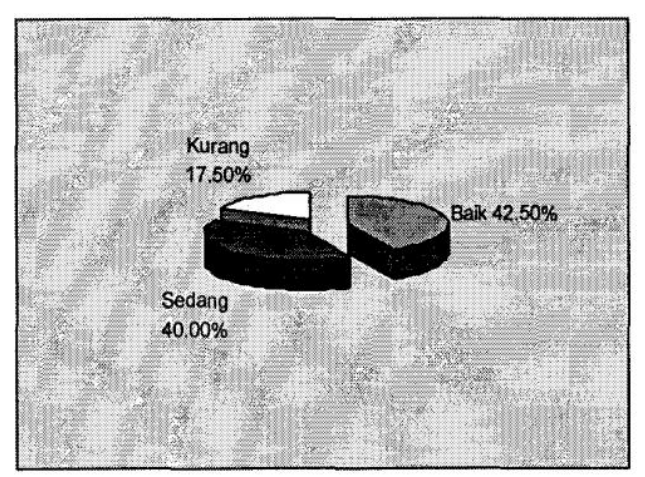

Hasil pemaparan data penelitian tersebut membuktikan bahwa pendekatan pembelajaran dengan media pengajaran (peraga) dalam kegiatan belajar mengajar, dapat 
meningkatkan motivasi

belajar siswa dalam kegiatan

belajar mengajar sehingga

berpengaruh terhadap minat belajar siswa Kelas X SMK

Negeri 1 BENDO Kabupaten

Magetan dalam belajar.

\section{HASIL PENELITIAN}

Berdasarkan pada paparan data observasi dan catatan selama penelitian tindakan yang berjudul Meningkatkan Minat Belajar Pendidikan Kewarganegaraan Pokok Bahasan Hukum dan Peradilan Nasional pada Siswa Kelas X SMK Negeri 1 BENDO Semester I Tahun Pelajaran 2014/2015 dengan Menggunakan Media Pengajaran, maka didapatkan hash penelitian sebagai berikut:

1. Dengan menggunakan media pengajaran dalam kegiatan belajar mengajar pada siswa Kelas X SMK Negeri 1 BENDO Kabupaten Magetan, dalam penyampaian mata pelajaran menjadi lebih baku. Setiap siswa yang melihat atau mendengar penyajian melalui media menerima pesan yang sama, meskipun guru menafsirkan isi pelajaran dengan cara yang berbeda-beda, dengan penggunaan media ragam hasil tafsiran itu dapat dikurangi sehingga informasi yang sama dapat disampaikan kepada siswa sebagai landasan untuk pengkajian, latihan, dan aplikasi lebih lanjut.

2. Pengajaran lebih menarik, sebab kejelasan dan keruntutan pesan, daya tank image yang berubah-ubah dapat menyebabkan siswa terawa dan berfikir, yang kesemuanya menunjukkan bahwa media memiliki aspek motivasi dan meningkatkan mirtat belajar siswa Kelas X SMK Negeri 1 BENDO Kabupaten Magetan.

3. Selama kegiatan belajar mengajar berlangsung, pembelajaran lebih interaktif dan menarik, sebab waktu pengajaran hanya membutuhkan waktu yang singkat dalam 
mengantarkan pesan-pesan isi pelajaran dalam jumlah yang cukup banyak dan siswa dapat menyerap isi pelajaran secara optimal.

4. Dengan menggunakan media pengajaran dalam Kegiatan belajar mengajar pada siswa Kelas X SMK Negeri 1 BENDO Kabupaten Magetan, tugas dan peran guru berubah kearah yang lebih positip. Artinya beban guru untuk menjelaskan yang berulangulang mengenai isi pelajaraii dapat dikurangi dan bahkan dihilangkan sehingga guru dapat memusatkan perhatian kepada aspek penting lain dalam proses belajar mengajar.

5. Dan uraian hasil penelitian tersebut dapat disimpulkan bahwa dengan menggunakan media bermedia pengajaran dalam kegiatan belajar mengajar, xnenurijukkan bahwa aktivitas, motivasi, dan prestasi belajar siswa Kelas
$X$ SMK Negeri 1 BENDO

Kabupaten Magetan mengalami peningkatan. Sehingga dapat ditegaskan bahwa dengan penggunaan media pengajaran dalam kegiatan belajar mengajar memiliki dampak positif terhadap belajar siswa, sebab umumnya siswa lebih senang melihat media pengajaran dan pada memperhatikan tulisan yang belum dimengerti dan dipahami. Pada akhirnya media bermedia pengajaran merupakan solusi terbaik bagi siswa Kelas X SMK Negeri 1 BENDO Kabupaten Magetan dalam mencapai tujuan belajar.

Bagaimana memilih media pengajaran yang baik?

Dalam memilih media pengajaran yang baik hams didasarkan pada kriteria pemilihan media bersumber dan konsep bahwa media merupakan bagian dan sistem instruksional secara 
keseluruhan. Untuk itu ada beberapa kriteria yang patut diperhatikan dalam memilih media. Diantaranya:

1. Sesuai dengan tujuan yang ingin dicapai.

Media dipilih berdasarkan tujuan instruksional yang telah ditetapkan yang secara umum mengacu kepada salah satu atau gabungan dan dua atau tiga ranah kognitif, afektif, dan psikomotor. Tujuan mi dapat dimedia ajarkan dalam bentuk tugas yang hams dikerjakan atau dipertunjukkan oleh siswa, seperti menghafal, melakukan kegiatan yang melibatkan kegiatan fisik atau pemakaian pninsipprinsip seperti sebab dan akibat, melakukan tugas yang melibatkan pemahaman konsepkonsep atau hubungan-hubungan

perubahan, dan mengerjakan tugastugas yang melibatkan pemikiran pada tingkatan lebih tinggi.

2. Tepat untuk mendukung isi pelajaran yang $s$ konsep, prinsip, atau generalisasi.

Media yang berbeda, misalnya film dan grafik memerlukan simbol dan kode yang berbeda, oleh karena itu memerlukan proses dan keterampilan mental yang berbeda untuk memahaminya. Agar dapat membantu proses pembelajaran secara efektif, media hams selaras sesuai dengan kebutuhan tugas pembelajaran dan kemampuan mental siswa. Televisi, misalnya, tepat untuk 
mempertunjukkan

proses transformasi

yang memerlukan

manipulasi ruang dan

waktu.

3. Praktis, luwes, dan bertahan.

Jika tidak tersedia waktu, dana, atau sumber daya lainnya untuk memproduksi, tidak perlu dipaksakan. Media yang mahal dan memakan waktu lama untuk memproduksinya bukanlah jaminan sebagai media yang terbaik. Kriteria mi menuntun para guru/instruktur untuk memilih media yang ada, mudah diperoleh, atau mudah dibuat sendiri oleh guru. Media yang dipilih sebaiknya dapat digunakan dimanapun dan kapanpun dengan peralatan yang tersedia di sekitarnya, serta mudah dipindahkan dan dibawa ke mana saja.

4. Guru terampil menggunakannya. ini merupakan salah satu kriteria utama. Apa pun media itu, guru hams mampu menggunakannya dalam proses pembelajaran. Nilai dan manfaat media amat ditentukan oleh guru yang menggunakannya. Proyektor transparansi (OHP), proyektor slide dan film, komputer, dan peralatan canggih lainnya tidak akan mempunyai arti apaapa jika guru belum dapat menggunakannya dalam proses pembelajaran sebagai upaya mempertinggi mutu dan hasil belajar. 
5. Pengelompokan

Sasaran.

$\begin{array}{lr}\text { Media } & \text { yang } \\ \text { elektif } & \text { untuk } \\ \text { kelompok } & \text { besar } \\ \text { belum tentu } & \text { sama } \\ \text { efektifnya } & \text { jika } \\ \text { digunakan } & \text { pada } \\ \text { kelompok kecil } & \text { atau } \\ \text { perseorangan. } & \text { Ada } \\ \text { media yang } & \text { tepat } \\ \text { untuk jenis kelompok } \\ \text { besar, kelompok } \\ \text { sedang, } & \text { kelompok } \\ \text { kecil } & \\ \text { perseorangan. } & \end{array}$

\section{PENUTUP}

Berdasarkan catatan dan observasi hasil penelitian tindakan tersebut, dalam penelitian tindakan yang berjudul "Meningkatkan Minat Belajar

Pendidikan Kewarganegaraan Pokok Bahasan Hukum dan Peradilan Nasional pada Siswa Kelas X SMK Negeri 1 BENDO Semester I Tahun Pelajaran 2014/2015 dengan Menggunakan Media Pengajaran" dapat disimpulkan bahwa penggunaan media pengajaran dalam kegiatan belajar mengajar dapat:
1. Memperjelas penyajian dan informasi sehingga dapat memperlancar dan meningkatkan motivasi, aktivitas dan hasil belajar.

2. Menimbulkan motivasi belajar, interaksi yang lebih langsung antara siswa dan lingkungannya, dan memungkinkan siswa untuk belajar sendiri sesuai dengan kemampuan dan minatnya, sehingga berpe ngaruh positif terhadap aktivitas belajarnya di kelas.

3. Memberikan kesamaan pengalaman kepada siswa tentang peristiwa peristiwa di lingkungan mereka, sehingga konsep tujuan yang direncanakan guru akan lebih baik bila dibandingkan dengan pemahaman isi pelajaran yang berbeda dan setiap siswa.

4. Digunakan untuk perorangan, kelompok, atau kelompok yang besar jumlahnya, dengan memiliki tiga fungsi utama diantaranya, (a) memotivasi minat dan tindakan, (b) menyajikan 
informasi, dan (c) memberi instruksi.

Berdasarkan kesimpulan hasil penelitian tersebut, maka dapat dirumuskan beberapa saran sebagai berikut:

1. Guru hendaknya lebih kreatif dalam melakukan inovasi dalam kegiatan belajar mengajar. Salah satunya adalah inovasi dalam menggunakan media pengajaran,

2. Lembaga sekolah hendaknya memberikan kesempatan kepada guru, dalam upaya meningkatkan motivasi belajar siswa dengan melengkapi sarana penunjang dalam kegiatan belajar mengajar. Sarana yang dimaksudkan adalah media pengajaran,

3. Siswa akan lebih memahami dan menerima hasil belajar, bila dalam penyampaian materi pelajaran yang dilakukan oleh guru bersifat kongrit, artinya siswa tidak verbalisme terhadap materi yang disampaikan oleh guru, sehingga dalam hal ini guru dituntut untuk lebih aktif dan kreatif dalam menggunakan media pengajaran. 


\section{DAFTAR PUSTAKA}

Arsyad, A. 2003. Media Pengajaran.

Jakarta: PT Raja Grafindo

Persada

Moleong, L. J. 2001. Metodologi

Penelitian Kualitatif.

Bandung: PT. Remaja

Rosdakarya.

Nasution, S. 1988. Metode Penelitian

Nuturalistik Kualitatif.

Bandung: Penerbit Tarsito

Spradley, J., P. 1980. Participant

Observation. New York:

Holt, Rinehart and Winston

Sudjana, N. dan Rival, A. 1990. Media Pengajaran. Bandung:

Penerbit CV. Sinar Baru

Bandung.

Zuriah, N. 2003. Penelitian Tindakan dalam Bidang Pendidikan dan Sosial. Edisi

Pertama. Malang: Bayu Media Publishing. 